\title{
Personal Entrepreneurial Competencies of the Business Students at Kalinga State University: A Basis for Enhancement of Teaching Strategies and Development of Program Structure
}

\author{
Karen Razelle M. Duyan* \\ Kalinga State University, Philippines; karenrazellemina@rocketmail.com
}

\begin{abstract}
Objectives: The study is to find out the individual entrepreneurial competencies of the business students at Kalinga State University be able to propose Instruction Strategies and Program Structure. Methods/statistical analysis: A 55 item questionnaire covering ten personal entrepreneurial competencies (PEC), was utilized which focuses on the following entrepreneurial competencies: Ability to find business possibilities, Perseverance, Dedication to their endeavors, Passion for Quality Outputs and Efficiency, Willingness to undertake risk, Target Setting, The pursuit of Knowledge, Well-organized Planning and Practical Monitoring, Ability to influence people, and Belief in oneself. The score per PEC trait was measured by summing a constant. Graphs were used to illustrate the result. Findings: The overall PECS rating of the students is found to be moderate. Entrepreneurial competencies of the Ability to influence people and Self-reliance can be concluded as their strengths because it is where they obtained the highest scores. They are found moderate on the Ability to find business possibilities, Dedication to their endeavors, the desire for Quality and Production Efficiency, Risk Taking, The pursuit of Knowledge, Well-organized Planning and Practical Monitoring, and Ability to influence people. Both sexes are found moderate on their overall rating, the male respondents got a higher rating on all of the competencies assessed except for Passion for Quality Outputs and Efficiency. Among the three programs assessed, Financial Management and the Office Administration students enrolled in the subject Entrepreneurship got the highest overall PEC rating of 16.79 followed by Entrepreneurship students who are undergoing Business Implementation who got 16.26 PEC rating and students who are taking up Entrepreneurship and Business Plan subject with 16.24 PEC rating. Application/improvements: The study suggests that measures should be taken to improve the student's competencies on Target Setting and Perseverance through training, and exposure to fieldwork and development of instructional materials.
\end{abstract}

Keywords: Entrepreneurship, Competencies, Strategies, Business

\section{Background of the Study}

Students taking up business-related courses will become future businesspeople or sales managers and executives so, $\underline{1}$ it is of utmost importance for the teachers and the university to know and understand the competencies of the business students in terms of entrepreneurship. In improving this competency, the university shares an indispensable role. 2 It is in the university that these future entrepreneurs or business managers and administrators are supposed to get the knowledge and the proper mindset they need for their ensuing entrepreneurial pursuance. It is by formal training that students acclimate themselves to grow successful as practicing entrepreneurs. In general, this study is pivoted on appraising the levels of entrepreneurial competencies of the students of the Kalinga State University in their fourth year and are enrolled during the first semester of SY 2018-2019. The assessment was conducted taking into consideration the following entrepreneurial competencies: Ability to find

${ }^{*}$ Author for correspondence 
business possibilities, Perseverance, Dedication to their endeavors, Passion for Quality Outputs and Efficiency, Willingness to undertake risk, Target Setting, The pursuit of Knowledge, Well-organized Planning and Practical Monitoring, Ability to influence people and Belief in oneself. The study distinguishes the competency levels of the said programs, and from the results, the researcher arrived up with recommendations geared toward strengthening the teaching strategies Development of Program Structure to be adopted by the CBEA faculty.

\section{Statement of the Problem}

This research is directed at uncovering the level of individual entrepreneurial competencies the Business students of the Kalinga State University in their fourth year and are enrolled during the first semester of SY 2018-2019.

Specifically, it seeks to answer the following questions:

1. What is the profile of respondents in terms of:
1.1 Gender
1.2 Program

2. What is the level of Entrepreneurial Competencies of respondents in terms of:

2.1 Ability to find business possibilities

2.2 Perseverance

2.3 Dedication to their endeavors

2.4 Passion for Quality Outputs and Efficiency

2.5 Willingness to undertake risk

2.6 Target Setting

2.7 The pursuit of Knowledge

2.8 Well-organized Planning and Practical Monitoring

2.9 Ability to influence people

2.10 Belief in oneself

3. What Teaching Strategies and should be adopted by the CBEA faculty and what Development of Program Structure should be introduced?

\section{Objectives of the Study}

The study attempts to ascertain the individual entrepreneurial competencies of the Business students of the Kalinga State University SY 2018-2019, and propose an action plan for Enhancement of Teaching Strategies and for the Development of Program Structure.

\section{Significance of the Study}

It is hoped that this study benefits the following:

\subsection{Administrators}

Through this study, a more practical way of training students enrolled in the CBEA will be formed. It will provide the ongoing program innovation of instructional materials, which are appropriate, appealing, significant, and sensitive to the students' needs.

\subsection{Entrepreneurship Subject Teacher}

The use of the result in this study will enable the teacher to choose tactics that he would make the teaching-learning method more significant.

\subsection{Students}

The use of improved teaching strategies will allow the students to comprehend the subject matter, which would give them the interest and the capability to master the concepts.

\subsection{Curriculum Writers}

This study may serve as an eye-opener for curriculum writers to see the need to produce instructional materials using the newly developed teaching strategies that will answer the needs of students.

\subsection{Future Researchers}

This study will assist as a premise for future research work in the teaching of Entrepreneurship. The findings of this study may be of use as initial input for future researches.

\section{Scope and Delimitation}

The respondents in this research activity are The Fourth Year students enrolled in Entrepreneurship Financial Management and Hotel and Restaurant Management and Office Administration of the Kalinga State University SY 2018-2019, enrolled during the first semester and further delimited to those who are enrolled in Entrepreneurship related subjects. 


\section{Survey Literature}

Reference ${ }^{3}$ described these competencies as correlated consciousness, perspective and abilities that a person can only get from educating himself through proper training and development.

Entrepreneurship according to reference 4 is the capability of an individual to determine the kind of product he should produce in order to meet the demand of the consuming public and be able to satisfy their wants and needs. It is a science of transforming theories into a business, a commercial or mercantile pursuit involved in as a means of livelihood. The entrepreneur is one who designs, operates, and accepts the uncertainties of a business enterprise. $\underline{5}$ These opportunities are evermore present considering that no man can obtain all the goods and services.

In ${ }^{6}$ Entrepreneurship is discovering novel business opportunities and organizing economic capital to exploit a new business opportunity or restructure an already operational one despite the uncertainty of making profits.

$\operatorname{In}^{\underline{Z}}$ Entrepreneurship plays a vital aspect of contemporary economics as it makes accessible, not only transformation but job generation and also national opulence. The heightening and thriving of enterprises and small businesses are equivalent to economic elevation. $\operatorname{In} 8$ Entrepreneurship is not limited to the accumulation of the applicable knowledge, skills, and attitude. Instead, it is visualized as continuous learning and conceptualized in terms of the unceasing progress of an individual's vital entrepreneurial capabilities.

$\mathrm{In}^{2}$ the analysis on the levels of entrepreneurial competencies of practicing entrepreneurs explained that they were most vulnerable in the Ability to find business possibilities, Willingness to undertake risk, and Belief in oneself. Practicing entrepreneurs were weakest in Risk Taking. Commonly, the competencies of students do not significantly vary by school, age, gender, nor year. The research has confirmed that educational institutions may affect the competency levels of students especially along with the areas of Ability to find business possibilities, Willingness to undertake risk, and Belief in oneself. $\underline{10}$ It is observed that among students who belong to the intermediate level, the quality of entrepreneurship education my affect their learning and characteristics.

In 11 students with training in entrepreneurship have higher entrepreneurial traits, higher achievement impulse, more individual control, and greater Self-reliance than a similar group. $\underline{12}$ Students who engage in business investments have more prominent entrepreneurial inclinations. They have more individual power, prominent Belief in oneself, and notably more innovative than the others.

\section{Locale of the Study}

The study was conducted at the Kalinga State University, Dagupan and Bulanao Campus, Tabuk City, Kalinga.

\section{Research Design}

The study utilized the descriptive method of the research with the questionnaire and interview as the primary tool in putting together the relevant data required in the study.

\section{Respondents of the Study}

The respondents in this research activity are 18students in Entrepreneurship, 27 students in Financial Management and Office Administration and 36 Fourth Year Hotel and Restaurant Management of the Kalinga State University SY 2018-2019, who are enrolled in the following subjects; Business Implementation, Entrepreneurship and Entrepreneurship and Business Plan respectively.

\section{Data Gathering Procedure}

The researcher obtained permission from the Dean of the CBEA and the faculty concerned to allow the researcher to conduct the study; after that, the researcher individually approaches the respondents to solicit their responses. Items not clearly understood by the respondents are translated in the vernacular for better comprehension.

\section{Method of Analysis}

In $\underline{13}$ a survey instrument was utilized based on the study Alusen ML, 2016, of as the primary data gathering instrument, Referred by from the earlier research of the Management Systems International and McBer and Company which was slightly revised to make it easier for the students to understand. The self-scoring individual entrepreneurial competency (PEC) questionnaire uses 55 questions to ascertain ten individual entrepreneurial competencies. Adapted from the study of $\underline{14}$ Using a 
5-point Likert scale with the following numerical and adjectival rating 1 - never, 2 - rarely, 3 - sometimes, 4 - usually, and 5 - always. The survey instruments have a sequential number to trace the answers of the respondents. Observation and casual conversation to the respondents were likewise employed for verifying the outcome of the study. PEC scores were calculated after getting the respondents' scale ratings. The score per PEC trait was computed by adding a constant. It followed the interpretation of PEC scores used in Table 1.

Table 1. Interpretation of PEC scores

\begin{tabular}{|l|l|}
\hline PEC scores & Interpretation of PEC \\
\hline 19 and up & Strong \\
\hline 16 to 18 & Moderate \\
\hline 15 and below & Weak \\
\hline
\end{tabular}

\section{Results and Discussion}

This chapter presents the analysis and interpretation of data in chronological order based on the statement of the problem. For a more reliable conclusion of readers, data were presented along with the discussion.

Figure 1 shows the individual demographic profile of students; the total number of respondents is 81 . Out of the 81 respondents, 18 are BS Entrep, 36 are BS HRM, and 27 are BSBA and BSOA students. There were more females than male respondents with the female comprising $74 \%$ and male $26 \%$ of the sample.

Figure 2 reflects that the male respondents get a higher PEC score than their female counterparts on all of the entrepreneurial competencies, except the Passion for Quality Outputs and Efficiency, although both male and

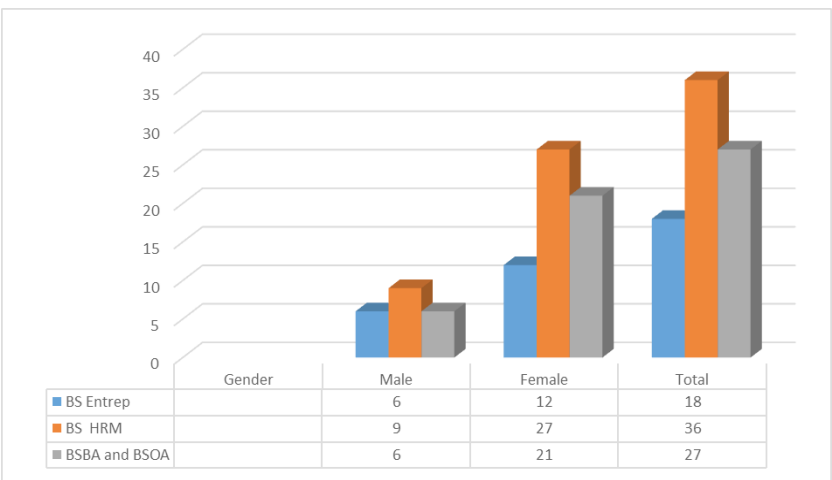

Figure 1. Demographic profile of students according to gender. female respondents are found moderate on their overall rating with 17.66 and $16.64 \mathrm{PEC}$ scores respectively.

Figure 3 summarizes the mean scores, interpretation, and ranking of the IndividualEntrepreneurial Competency Scores of 18 Fourth Year BS Entrepreneurship, 27 Fourth Financial Management and Office Administration and 36 Fourth Year Hotel and Restaurant Management of the Kalinga State University.

It presents the level of individual entrepreneurial competency of the 81 fourth-year students enrolled during the first semester of SY 2018-2019 enrolled in Entrepreneurship related subjects. The students have 16.43 , as their weighted mean, which means a MODERATE level of entrepreneurial competency.

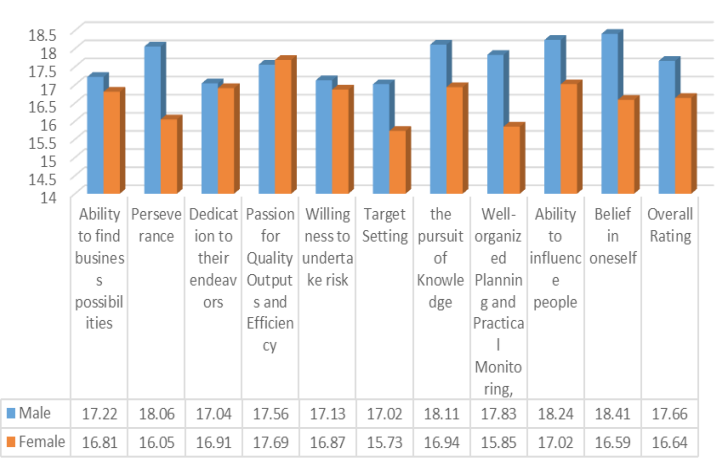

Figure 2. Personal entrepreneurial competencies of the respondents in terms of gender.

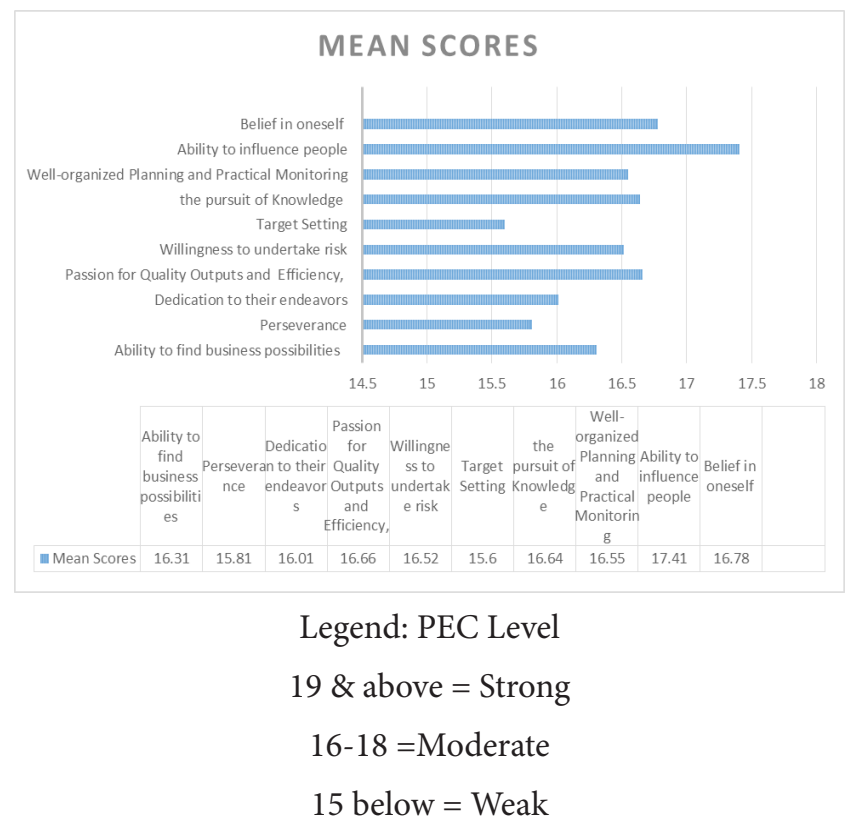

Figure 3. Personal entrepreneurial competency scores. 
They were found to be moderate in Ability to influence people and Networking with a PEC score of 17.41, on Ability to find business possibilities 16.31, Passion for Quality Outputs and Efficiency 16.01, on The desire for Quality and Production Efficiency 16.66, Well-organized Planning and Practical Monitoring 16.55, on Risk Taking 16.52, on The pursuit of Knowledge 16.64 and 16.78 on Belief in oneself. The students were, however, found weak on Target Setting and Persistence with 15.60 and 15.81 PEC scores, respectively. Ability to influence people and Networking are the leading competencies that the respondents have, which means they can make people change the way they think, feel or behave and they can use a variety of techniques to influence the mind of others. Second is Belief in oneself, which confirms the observation of the teachers handling the subjects that their students would normally seek autonomy from the rules and control of others.

The pursuit of Knowledge came fourth in the ranking of PEC scores despite the massive influence of social media, maybe because of the limited knowledge of the students on how technology can advance their skills in entrepreneurship.

They scored moderately On Dedication to their endeavors, which suggests that they have an average loyalty to work engagement and scantly keen on the deadline established to fulfill a duty. They have to develop on their sense of taking full responsibility in taking a job and must obtain knowledge that success does not come easy. The respondents are weakest; however, on Target Setting, which infers that they are not able to make an action plan or design toward a Target, which is a vital competency in Entrepreneurship. When asked during the interview, one of the respondents concurred that the final year of her studies she still does not know what it is that she wanted to do after she graduated in college. They also need to learn how to set practical and achievable objectives.

Figure 4 sums up the mean scores, interpretation, and ranking of the Personal Entrepreneurial Competency Scores of BS Entrepreneurship Students. In general, the BS Entrepreneur students were established to be moderate on OpportunitySeeking, Persistence, Risk Taking, Target Setting, The pursuit of Knowledge, Systematic/Orderly Planning and Efficient Monitoring, Persuasion and Networking, and Self Confidence. They are found weak on the desire for Quality and Production Efficiency and The desire for Quality and Production Efficiency with a PEC score of 15.00 and 15.78 respectively

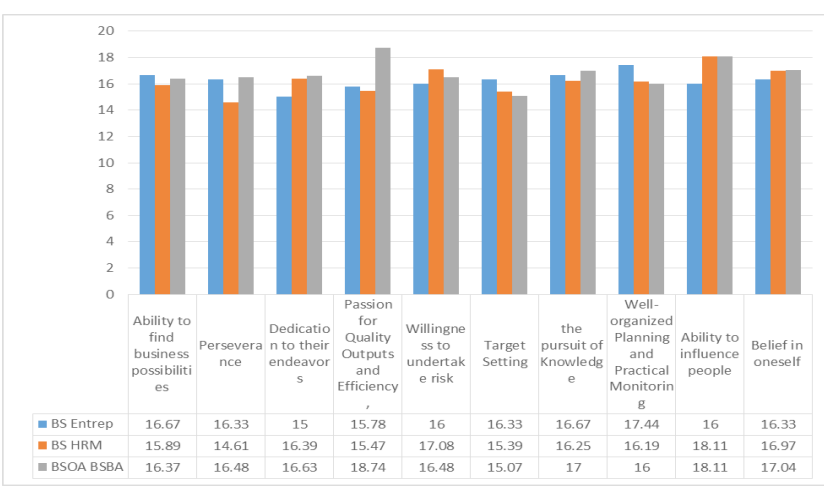

Figure 4. Entrepreneurial competencies scores of the business students of Kalinga State University.

It encapsulates the mean scores, interpretation, and ranking of the Individual Entrepreneurial Competency Scores of BS Hotel and Restaurant Management. In general, the BS Hotel and Restaurant Management students were found to be moderate in Passion for Quality Outputs and Efficiency, Risk Taking, The pursuit of Knowledge, Seeking, Well-organized Planning and Practical Monitoring, Ability to influence people and Networking and Self Confidence. They are found weak on the Ability to find business possibilities, Persistence, Passion for Quality Outputs and Efficiency, and Target Setting.

It outlines the mean scores, interpretation, and ranking of the Individual Entrepreneurial Competency Scores of BS Hotel and Restaurant Management. In general, the BS Hotel and Restaurant Management students were found to be moderate in Passion for Quality Outputs and Efficiency, Risk-Taking, The pursuit of Knowledge, Seeking, Systematic Planning and Monitoring, Ability to influence people and Networking, on Ability to find business possibilities, Persistence, Passion for Quality Outputs and Efficiency and Self Confidence. They are found weak only on Target Setting.

\section{Conclusion}

The overall PECS rating of The Fourth Year BS Entrepreneurship, BSBA Major in Financial Management, BS Hotel and Restaurant Management and BS Office Administration in Kalinga State University SY 20182019 is moderate. Entrepreneurial competencies of the Ability to influence people and Networking and Belief in oneself can be concluded as their strengths because it is where they obtained the highest scores. However, 
they should focus on developing their competencies on Target Setting and Persistence, which got the lowest PEC scores categorized as weak. They are found moderate on the Ability to find business possibilities, the desire for Quality and Production Efficiency, Passion for Quality Outputs and Efficiency, Risk Taking, The pursuit of Knowledge, Systematic Planning and Monitoring, and Ability to influence people and Networking. Although both male and female respondents are found moderate on their overall rating, the male respondents got a higher rating on all of the entrepreneurial competencies assessed except for Passion for Quality Outputs and Efficiency. Among the three programs assessed, BSBA FM and BSOA students enrolled in the subject Entrepreneurship got the highest overall PEC rating of 16.79 followed by BS Entrepreneurship students who are undergoing Business Implementation who got 16.26 PEC rating and students who are taking up Entrepreneurship and Business Planning subject with 16.24 PEC rating.

\section{Recommendations}

To improve the individual entrepreneurial competency levels of the students, it is needed that:

(1) KSU should review the curriculum for the three programs; it should prioritize and include activities that will encourage them to develop their entrepreneurship competencies, especially on Target Setting and Persistence. There should be an innovation of instructional materials, which are relevant, engaging, meaningful, and responsive to the student's needs for the development of their Entrepreneurship and Business Planning Skills.

(2) KSU should put up a mini-enterprise managed by the students or the student organizations, this way the students will experience practical learning and exposure to fieldwork which would further their strength in the Ability to influence people and Networking and Belief in oneself and will help develop the other competencies.

(3) The students should be encouraged and given support when attending local and International forums or symposia, trade fairs, and exhibits that will develop their entrepreneurial competencies.

(4) It is recommended that the students should undergo the following suggested training which focuses on identifying Business Ideas and Opportunities, entrepreneurship and business planning, Willingness to undertake risk in entrepreneurial decisionmaking and strategic Networking for Entrepreneurs.

(5) Regular mentoring and coaching programs should be made available for the students who want to learn from local and successful entrepreneurs through a partnership with the Department of Trade and Industry or the Kalinga Chamber of Commerce.

\section{References}

1. Business university student entrepreneurial competencies: towards readiness for globalization. [cited 2015 Sep]. https:// www.researchgate.net/publication/291809763_Business_ University_Student_Entrepreneurial_Competencies_ Towards_Readiness_for_Globalization.

2. Alusen ML. Personal entrepreneurial competencies of LPU-Laguna BSBA graduating students: basis for curriculum enhancement. LPU Laguna J Multidiscip Res. 2016;4(4):92-105.

3. Inyang BJ, Enuoh RO. Entrepreneurial competencies: the missing links to successful entrepreneurship in Nigeria. Int Bus Res. 2009;2(2):62-71.

4. Entrepreneurial marketing: the emergence of a new strategy in a small venture. [cited 2016]. http://www.diva-portal. org/smash/get/diva2:933983/FULLTEXT01.pdf.

5. Entrepreneurship unlimited opportunities and resources. [cited 2009]. http://stvlopac.sscrmnl.edu.ph/cgi-bin/koha/ opac-detail.pl?biblionumber $=67427$.

6. Paladan DB. Business university student entrepreneurial competencies: towards readiness for globalization. Adv Econ Bus. 2015;3(9):390-97.

7. Entrepreneurs and their impact on jobs and economic growth. [cited 2014]. https://wol.iza.org/uploads/articles/8/ pdfs/entrepreneurs-and-their-impact-on-jobs-andeconomic-growth.pdf.

8. Oganisjana K, Matlay H. Entrepreneurship as a dynamic system: a holistic approach to the development of entrepreneurship education. Ind High Educ. 2012;26(3): 207-16.

9. LaguadorJM.A correlation study of personal entrepreneurial competency and the academic performance in operations management of business administration students. Int J Acad Res Bus Soc Sci. 2013;3(5):61-4.

10. de Lourdes Cárcamo-Solís M, delPilar Arroyo-López M, del Carmen Alvarez-Castañón L, García-López E. Developing entrepreneurship in primary schools. The Mexican experience of "My first enterprise: entrepreneurship by playing. Teach Educ.2017;64:291-304. 
11. Kerr SP, Kerr WR, Xu T. Personality traits of entrepreneurs: a review of recent literature. Found Trends Entrep. 2018;14(3):279-356.

12. Adegbite SA, Ilori MO, Irefin IA, Abereijo IO, Aderemi HOS. Evaluation of the impact of entrepreneurial characteristics on the performance of small scale manufacturing industries in Nigeria. J Asia Entrep Sustain. 2007;3(1):1-22.

13. Paladan NN. Transformational leadership: the emerging leadership style of successful entrepreneurs. J Lit Art Stud. 2015;5(1):64-72. 